\title{
Stricture at colorectal anastomosis: to dilate or to incise
}

\section{(ㄷ)(이우}

\begin{abstract}
Authors
Wiriyaporn Ridtitid ${ }^{1}$, Aroon Siripun ${ }^{2}$, Rungsun Rerknimitr ${ }^{1}$

Institutions

1 Division of Gastroenterology, Department of Medicine, Chulalongkorn University and King Chulalongkorn Memorial Hospital The Thai Red Cross, Bangkok, Thailand

2 Division of Gastroenterology, Department of Medicine, Bangkok Hospital, Bangkok Thailand.
\end{abstract}

Bibliography

DOI https://doi.org/10.1055/s-0043-122495 |

Endoscopy International Open 2018; 06: E340-E341 (c) Georg Thieme Verlag KG Stuttgart · New York ISSN 2364-3722

Corresponding author

Rungsun Rerknimitr, MD, Professor of Medicine, Division of

Gastroenterology, Department of Medicine, Faculty of

Medicine, Chulalongkorn University, Bangkok 10330,

Thailand

Fax: +66-2-252-7839

ERCP@live.com
Benign colonic anastomotic stricture is one the main complications developed after colectomy, it occurred in up to $22 \%$ of patients undergoing colorectal resection [1]. In practice, management of postoperative anastomotic strictures includes endoscopic balloon dilation (EBD), insertion of self-expandable metal stent, repeat surgery, and colostomy. Due to its effectiveness, simplicity, and safety, EBD is always the first choice [2, 3]. Nevertheless, multiple sessions of EBD may be required to achieve long-term patency. Moreover, approximately one-fifth of patients initially managed by EBD required additional treatment, including stent insertion and/or revisional surgery [3]. The failure of EBD may be explained by traumatic injury to the deeper muscle layer from repeated EBD, resulting in formation of cicatrized and contracted new scar tissues [4].

Recently, an endoscopic electrocautery incision (EEI) technique has been reported as an alternative treatment for anastomotic colorectal strictures [5-7]. Radial incisions were performed using either a precut sphincterotome $[5,7]$ or an insulated tip (IT) knife [6]. However, location, depth and length of the incision in each series were different because these were left to the discretion of the endoscopists. Four case series $(n=76)$ showed good efficacy for EEl in combination with other endoscopic techniques including EBD, adjunctive corticosteroid injection, or Argon plasma coagulation (APC) [8-11]. Furthermore, three studies $(n=47)$ demonstrated the advantage of more aggressive EEl by adding a cutting method after finishing radial incision (RIC), which involves removal of the flaps that developed after radial incisions. In other words, RIC is more like "conization of cervical cancer" [12]. The only difference is that the scar tissue removed by RIC is more cylindrical shaped than cone shaped. In other words, RIC is the technique that "scoops" the deeper fibrotic scar ( $>$ Fig.1a) that may reform again after EBD ( $\triangleright$ Fig. 1b) or EEI ( $\triangleright$ Fig. 1c). A recent systematic review of 10 studies by Jain et al summarized experience in 186 patients with benign lower gastrointestinal tract anastomotic strictures undergoing EEl, either alone $(n=63)$ or in combination with another modality $(n=123)$ [13]. Of those, 47 patients underwent RIC. During long-term follow up, the initial success rates were $95.2 \%, 95.8 \%$, and $87.8 \%$ for EEI alone, RIC, and $\mathrm{EEI}$ with $\mathrm{EBD}$, respectively. Recurrent rates of strictures were $4.8 \%, 0 \%$, and $12.5 \%$ for $\mathrm{EEI}$ alone, RIC, and EEI with EBD, respectively. Based on these data, stricture recurrence rates in patients undergoing EEl either alone or in combination with RIC were much lower than that previously reported for EBD alone. More interestingly, no recurrent stricture was seen in those who underwent RIC. The advantage of RIC may be due to the technique that can directly excise the scar tissue which could be the cause of refractory stenosis.

In this issue of Endoscopy International Open, Asayama et al. demonstrated success in 3 patients undergoing RIC at the level of intraperitoneal colonic anastomotic strictures after failed EBD [14]. Of those, 2 patients had improvement following a single session and the other succeeded after 6 sessions. No procedure-related adverse events or recurrent stricture occurred during a median follow-up of 27 (range 8-37) months. Although this showed the effectiveness and safety of RIC in patients with benign anastomotic strictures, there are certain key issues that have to be addressed in this setting. First, estimation of the length of incision and the depth of cutting to avoid perforation is subject to the endoscopist's discretion. Second, the learning curve to reach competency in RIC may be steeper because it appears more difficult than conventional EEI. Perhaps endoscopists who are very experienced in endoscopic submucosal dissection (ESD) would be the preferred operators 


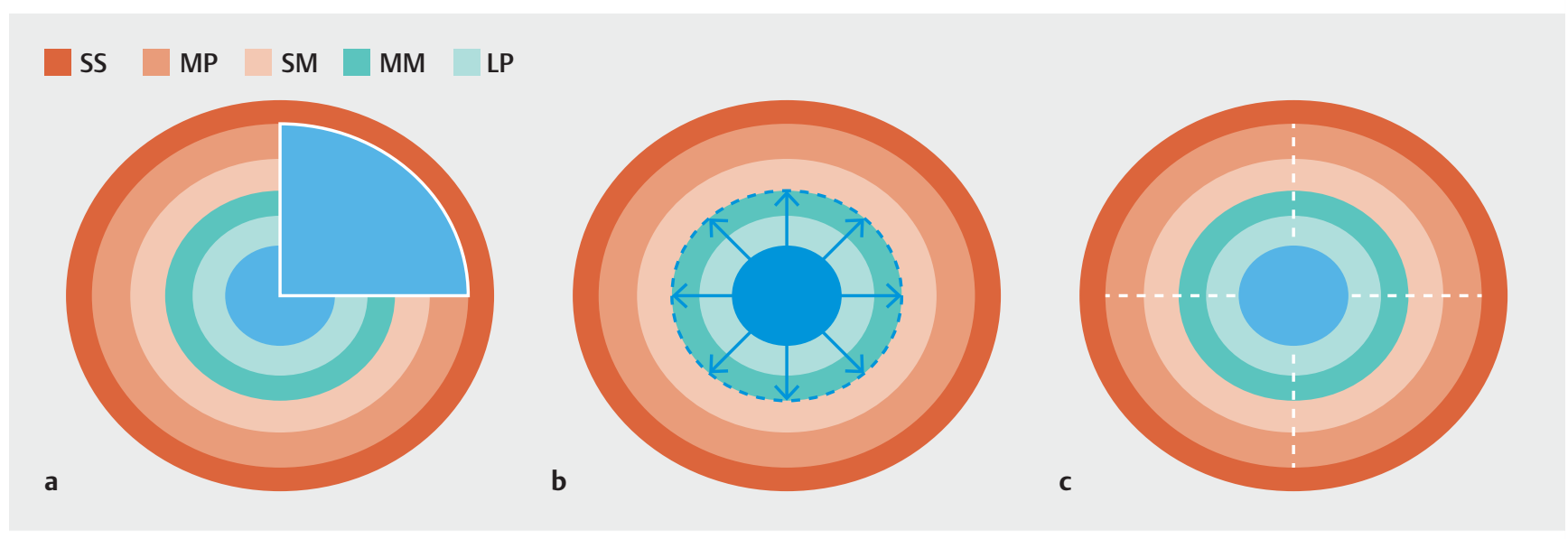

- Fig. 1 The cross section of the rectal anastomotic site (SS, serosa; MP, muscularis propria; SM, submucosa; MM, muscularis mucosae; LP, lamina propria): a Radial incision and cutting method (RIC; white lines), b Endoscopic balloon dilation (EBD; blue dashes), c Endoscopic electrocautery incision (EEl; white dashes)

for RIC. Third, the feasibility of RIC in a case with long stricture may be limited and the procedure may be dangerous. Fourth, this technique can lead to significant risks of bleeding, infection, and perforation, therefore, surgical back up is recommended. Perhaps there may be a role of colonic stenting as the rescue treatment for perforation that develops after RIC.

Although EBD is the current standard for primarily endoscopic management in patients with benign colorectal anastomotic strictures, it requires multiple dilations and results in a significant rate of restenosis. Given these data, conventional $\mathrm{EEI}$ is a promising technique for short anastomotic stricture. In our opinion, RIC may be better but more dangerous than conventional EEI ( $>$ Table 1 ). Therefore, we recommend that RIC be performed only by expert endoscopists. Randomized controlled trials comparing the outcomes of EBD, conventional $\mathrm{EEI}$, and RIC are warranted to confirm the long-term effectiveness and safety of the three techniques in treating benign colorectal anastomotic strictures.

\section{Competing interests}

None

\section{References}

[1] Luchtefeld MA, Milsom JW, Senagore A et al. Colorectal anastomotic stenosis. Results of a survey of the ASCRS membership. Dis Colon Rectum 1989; 32: $733-736$

[2] Araujo SE, Costa AF. Efficacy and safety of endoscopic balloon dilation of benign anastomotic strictures after oncologic anterior rectal resection: report on 24 cases. Surg Laparosc Endosc Percutan Tech 2008; 18: $565-568$

[3] Belvedere B, Frattaroli S, Carbone A et al. Anastomotic strictures in colorectal surgery: treatment with endoscopic balloon dilation. G Chir 2012; 33: 243-245

[4] Cheng YS, Li MH, Yang R] et al. Restenosis following balloon dilation of benign esophageal stenosis. World J Gastroenterol 2003; 9: 2605-2608
- Table 1 Comparison of efficacy and feasibility among the three techniques

\begin{tabular}{|l|l|l|l|}
\hline & EBD & EEI & RIC \\
\hline Technical difficulty & Easy & Difficult & More difficult \\
\hline Risk of perforation & + & ++ & +++ \\
\hline Effectiveness & & ++ & $+++(?)^{1}$ \\
\hline $\begin{array}{l}\text { EBD, endoscopic balloon dilation; EEI, endoscopic electrocautery incision; } \\
\text { RIC, radial incision and cutting method } \\
\text { 1 Require studies to confirm }\end{array}$ \\
\hline
\end{tabular}

[5] Wallstabe I, Teich N. Successful endoscopic incision of pouch-anal stricture in a patient with ulcerative colitis. Tech Coloproctol 2015; 19: $429-430$

[6] Kwon JH, Han KH, Kim MH et al. Two cases of electrocautery incision therapy using an insulated-tip knife for treatment of symptomatic benign short-segment colonic stenosis following colonic resection. Korean J Gastroenterol 2014; 64: 164- 167

[7] Bravi I, Ravizza D, Fiori G et al. Endoscopic electrocautery dilation of benign anastomotic colonic strictures: a single-center experience. Surg Endosc 2016; 30: 229-232

[8] Dieruf LM, Prakash C. Endoscopic incision of a postoperative colonic stricture. Gastrointest Endosc 2001; 53: 522 - 524

[9] Hagiwara A, Sakakura C, Shirasu M et al. Sigmoidofiberscopic incision plus balloon dilatation for anastomotic cicatricial stricture after anterior resection of the rectum. World J Surg 1999; 23: 717-720

[10] Truong S, Willis S, Schumpelick V. Endoscopic therapy of benign anastomotic strictures of the colorectum by electroincision and balloon dilatation. Endoscopy 1997; 29: 845-849

[11] Schubert D, Kuhn R, Lippert H et al. Endoscopic treatment of benign gastrointestinal anastomotic strictures using argon plasma coagulation in combination with diathermy. Surg Endosc2003; 17: 1579-1582

[12] Cooper DB, Menefee GW. Conization Of Cervix. In: StatPearls. edn. Treasure Island (FL);2017

[13] Jain D, Sandhu N, Singhal S. Endoscopic electrocautery incision therapy for benign lower gastrointestinal tract anastomotic strictures. Ann Gastroenterol2017; 30: 473-485

[14] Asayama $\mathrm{N}$ et al. Effectiveness and safety of endoscopic radial incision and cutting for severe benign anastomotic stenosis after surgery for colorectal carcinoma: a three-case series). Endosc Int Open2018; 06: E335-E339 